\title{
Interstitial lung disease-related pneumomediastinum in COVID-19 patients
}

\section{To the Editor:}

We read with interest the work of Lemmers et al. [1] published recently in this journal. We also found that spontaneous pneumomediastinum is an uncommon presentation of severe coronavirus disease 2019 (COVID-19) patients. The mechanisms of pneumomediastinum remain unclear [2]. From March 2020 to November 2020 we identified eight patients with pneumomediastinum at intensive care unit admission among 401 COVID-19 patients in two Seine-Saint-Denis hospitals in the Paris (France) area. Neither risk factor nor underlying respiratory disease was identified in these patients. Spontaneous pneumomediastinum occurred without mechanical ventilation (neither noninvasive nor invasive) for four patients and on the day following tracheal intubation despite lung-protective invasive ventilation for the others. Tracheal and bronchial integrity was verified by direct bronchoscopic examination and high-resolution chest computed tomography. As reported by Lemmers et al. [1], plateau pressure was constantly $<25 \mathrm{cmH}_{2} \mathrm{O}$ in the four patients under invasive mechanical ventilation, suggesting that pneumomediastinum were not related to barotrauma or traumatic tracheal intubation.

A similar observation was made in patients with severe acute respiratory syndrome in 2003 [3], but no physiopathological mechanism was identified. We here propose a hypothesis to explain pneumomediastinum in severe acute respiratory syndrome coronavirus 2 (SARS-CoV-2) infection. Some patients with severe COVID-19 present extensive ground-glass opacities which contribute to hypoxaemia, but also reflect the intense inflammatory process occurring in the lung (figure 1). The inflammation can generate a retractive process illustrated by the bronchiectasis and the pneumomediastinum. Such a phenomenon is also seen in acute exacerbation of idiopathic pulmonary fibrosis [4], pleuroparenchymal fibroelastosis or melanoma-differentiation-associated protein 5 related interstitial lung diseases [5]. The high speed of inflammation installation and lung architectural change in these conditions could possibly explain the onset of pneumomediastinum.

In COVID-19 patients with pneumomediastinum, we believe that physicians should consider initiation of anti-inflammatory treatment to stop retractive processes and should not refrain from using steroids for SARS-CoV-2 pneumonia.

Kim Blanc ${ }^{1,2}$, Nicolas Bonnet ${ }^{3}$, Elise Ouedraogo ${ }^{4,5}$, Michel Arnaout $^{6}$, Maxime Patout ${ }^{7,8}$ and Yacine Tandjaoui-Lambiotte ${ }^{3,9}$

${ }^{1}$ Intensive Care Unit, André Grégoire Hospital, Montreuil, France. ${ }^{2}$ Pulmonology Dept, André Grégoire Hospital, Montreuil, France. ${ }^{3}$ Intensive Care Unit, Avicenne Hospital, AP-HP, Bobigny, France. ${ }^{4}$ Sorbonne Paris Nord University, Bobigny, France. ${ }^{5}$ Infectious Diseases Dept, Avicenne Hospital, AP-HP, Bobigny, France. ${ }^{6}$ Intensive Care Unit, Antony Private Hospital, Antony, France. ${ }^{7}$ Sleep Diseases Dept R3S, PitiéSalpêtrière Hospital, AP-HP, Paris, France. ${ }^{8}$ INSERM, UMRS1158 Experimental and Clinical Respiratory Neurophysiology, Paris, France. ${ }^{9}$ INSERM U1272 Hypoxia and Lung, Bobigny, France.

@ERSpublications

Pneumomediastinum in severe \#COVID19 presentations could be due to a lung parenchymal retractive process generated by intense inflammation as in acute exacerbation of idiopathic pulmonary fibrosis or MDA-5 acute interstitial lung disease https://bit.ly/3qzBYMW

Cite this article as: Blanc $\mathrm{K}$, Bonnet $\mathrm{N}$, Ouedraogo $\mathrm{E}$, et al. Interstitial lung disease-related pneumomediastinum in COVID-19 patients. ERJ Open Res 2021; 7: 00014-2021 [https://doi.org/ 10.1183/23120541.00014-2021].

Copyright @ The authors 2021. This version is distributed under the terms of the Creative Commons Attribution NonCommercial Licence 4.0. For commercial reproduction rights and permissions contact permissions@ersnet.org 


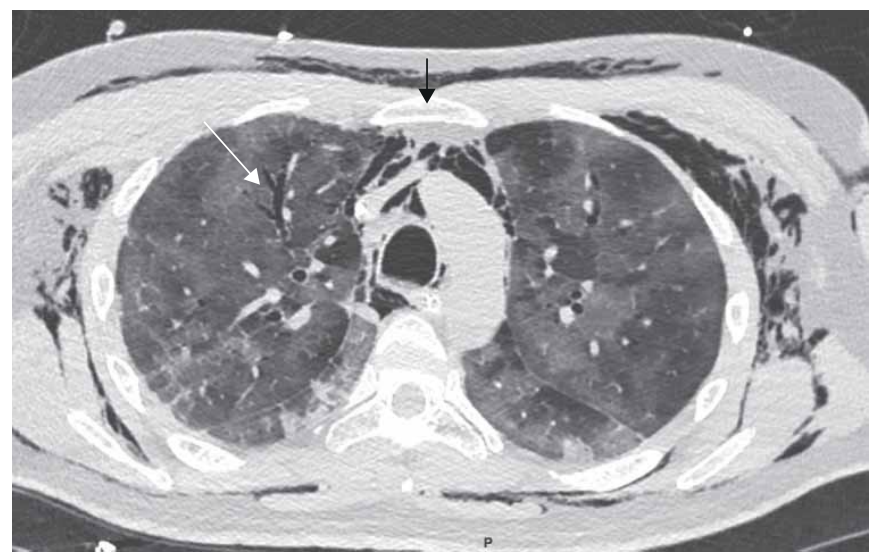

FIGURE 1 Ground-glass opacities in severe coronavirus disease 2019 reflect the intense inflammatory process occurring in the lung. The inflammation can generate a retractive process illustrated by the bronchiectasis (white arrow) and the pneumomediastinum (black arrow).

Correspondence: Yacine Tandjaoui-Lambiotte, Intensive Care Unit, Avicenne Hospital, AP-HP, 125 rue de Stalingrad, Bobigny 93000, France. E-mail: yacine.tandjaoui-lambiotte@aphp.fr

Received: 11 Jan 2021 | Accepted: 14 Jan 2021

Conflict of interest: K. Blanc has nothing to disclose. N. Bonnet has nothing to disclose. E. Ouedraogo has nothing to disclose. M. Arnaout has nothing to disclose. M. Patout reports personal fees and nonfinancial support from Resmed, Philips Respironics and Asten, outside the submitted work. Y. Tandjaoui-Lambiotte has nothing to disclose.

\section{References}

1 Lemmers DHL, Abu Hilal M, Bnà C, et al. Pneumomediastinum and subcutaneous emphysema in COVID-19: barotrauma or lung frailty? ERJ Open Res 2020; 6: 00385-2020.

2 Zhou C, Gao C, Xie Y, et al. COVID-19 with spontaneous pneumomediastinum. Lancet Infect Dis 2020; 20 : 510.

3 Chu CM, Leung YY, Hui JYH, et al. Spontaneous pneumomediastinum in patients with severe acute respiratory syndrome. Eur Respir J 2004; 23: 802-804.

4 Colombi D, Ehlers-Tenenbaum S, Palmowski K, et al. Spontaneous pneumomediastinum as a potential predictor of mortality in patients with idiopathic pulmonary fibrosis. Respiration 2016; 92: 25-33.

5 Kotsiou OS, Daniil Z, Gourgoulianis KI. Pneumomediastinum in MDA5-associated clinically amyopathic dermatomyositis. Rheumatol Adv Pract 2017; 1: rkx003. 